\title{
Research
}

\section{Experiences of using email for general practice consultations:}

\author{
a qualitative study
}

\begin{abstract}
Background

Reports suggest approximately $21-23 \%$ of GPs in the UK have consulted with patients using email, but little is known about the nature of this use and what it means for clinicians and patients in general practice.
\end{abstract}

\section{Aim}

To understand the use of email consultation in general practice by investigating the experiences of existing users and views of experts.

\section{Design and setting}

A qualitative study conducted in 2010 using purposive sampling and semi-structured interviews in general practice and community settings in some London boroughs.

\section{Method}

A maximum variation sample of GPs and patients who had used email for consultation in general practice were recruited, as were policy and/or implementation experts. Interviews continued until saturation was achieved.

\section{Results}

In total $10 \mathrm{GPs}, 14$ patients, and six experts were interviewed. Consultation by email was often triggered by logistic or practical issues; motivators for ongoing use were the benefits, such as convenience, for GPs and patients. Both GPs and patients reported concerns about safety and lack of guidance about the 'rules of engagement' in email consultations, with GPs also concerned about workload. In response, both groups attempted to introduce their own rules, although this only went some way to addressing uncertainty. Long term, participants felt there was a need for regulation and guidance.

\section{Conclusion}

Consultations by email in general practice occur in an unregulated and unstructured way. Current UK policy is to promote consultations by email, making it crucial to consider the responsibility and workload faced by clinicians, and the changes required to ensure safe use; not doing so may risk safety breaches and result in suboptimal care for patients.

\section{Keywords}

electronic mail; family practice; physicianpatient relations; qualitative evaluation.

\section{INTRODUCTION}

Email is a ubiquitous communication method; in 2009, $97 \%$ of UK adult internet users across all generations and demographic groups reported using email. Although the majority of professionals in industry routinely employ email, those in health care have not adopted this type of communication. ${ }^{2-4}$ Currently, there is no widely accepted way for patients to email their doctor, with healthcare professionals relying on more traditional methods such as the postal service and telephone. Levels of email use are reported at around 20-25\% for doctors across Europe and the US. ${ }^{5-8}$ For those doctors who have tried using email in practice, it has tended to be with small numbers of selected patients. ${ }^{9}$ In line with the widespread use of email, policymakers around the world have pressed for it to be used as a method for patients and healthcare professionals to communicate with each other. ${ }^{10-14}$

In some countries, email is more widely used by primary care professionals; for example, in Denmark, patients can engage in electronic communication with the GP via the official Danish health website. ${ }^{15}$ In the US, health-maintenance organisations have embraced email for consulting with their patients, ${ }^{16}$ and US medical organisations have provided guidelines relating to the use of email consultations. ${ }^{4,17}$ However, in the UK there are a lack of formal systems

H Atherton, MSc, MPH, PhD, National Institute for Health Research School for Primary Care Research Fellow; C Heneghan, MA, MRCGP, DPhil, clinical reader in evidence-based medicine, Department of Primary Health Care Sciences, University of Oxford, Oxford. Y Pappas, PhD, director of postgraduate programmes in health services research and public Health, City University London, London. E Murray, PhD, MRCGP, reader in primary care, University

College London, London.

\section{Address for correspondence}

Dr Helen Atherton, Department of Primary Care available for using email consultation and bodies representing medical professionals have largely advised against its use for consultation with patients. ${ }^{18-21}$ This is despite recent government policy, which stipulates that patients should be able to communicate electronically with their health and care team by 2015.'13

A reason for lack of engagement may be the scarcity of evidence underpinning its use. A Cochrane review on email for consultation found that all included trials were of low quality and inconclusive. ${ }^{22}$ However, email is already filtering into use between some doctors and patients, $7,8,23$ and there is potentially much to be learned from their experiences with email consultation.

This study aimed to understand the use of email consultation in English general practice outside of any formalised email consultation system, by investigating the experiences of existing users and the views of experts.

\section{METHOD}

The study was conducted in London, UK, in 2010. Semi-structured interviews were conducted with patients and GPs in primary care, and with experts on the use of email in primary care.

Participants were patients and GPs in primary care, as well as experts on the use of email in primary care. Eligibility criteria were that patients and GPs were required to

Health Sciences, University of Oxford, Radcliffe Observatory Quarter, Woodstock Road, Oxford OX2 6GG.

E-mail: helen.athertonaphc.ox.ac.uk

Submitted: 9 May 2013; Editor's response: 24 May 2013; final acceptance: 15 July 2013. @British Journal of General Practice This is the full-length article (published online 28 Oct 2013) of an abridged version published in print. Cite this article as: Br J Gen Pract 2013; DOI: 10.3399/bjgp13X674440 


\section{How this fits in}

Where there is evidence relating to email consultation use, it is frequently of low quality and does not explore experiences and perceptions of users. Surveys show that approximately $21-23 \%$ of doctors across the UK have engaged in email consultation at some point and policymakers are recommending its use. This study shows that, where email consultation is used in general practice, it brings perceived benefits for both patients and GPs. However, the current lack of 'rules of engagement' results in uncertainty for both GPs and patients about how to use email safely and appropriately. Many of the issues associated with email consultation could be addressed through guidelines and research into workload and safety issues.

have used, at least once, email for two-way communication when requesting or providing patient-specific information. Experts were selected for their expertise in factors relevant to the use of email for consultation purposes, namely policy, implementation, ethics, and information governance.

\section{Recruitment and sampling}

A purposive sampling strategy was used, identifying users of email consultation. Maximum variability for factors that may impact on use of email consultation was aimed for; these factors included age, sex, education, ${ }^{9,24}$ size of practice attended, ${ }^{25}$ and email-usage levels among patients, and sex, qualification date, and practice size for clinicians. ${ }^{25-27}$

GPs. GPs who were using email consultation were identified via the Primary Care Research Network (PCRN) and by screening practice websites in London and snowballing. The majority of GPs were recruited via snowballing: initial participants were linked to the academic department; they then put the researchers in touch with GPs who may be using email and so on (seven GPs). One GP practice (one GP) was recruited via a contact at the PCRN who knew the GP was using email with patients. After this, to broaden the sample one of the researchers screened all practice websites in the areas where the research team had research and development approval for NHS recruitment: Brent; Kensington and Chelsea; Hammersmith and Fulham; Southwark; Lambeth; Bromley; and Greenwich. This allowed recruitment of the final GP and practice manager.
Experts. Expert participants were identified via recommendations from participants and colleagues, and by searching online for experts in policy, implementation, ethics, and information governance. Potential participants were invited via email or letter to join the study.

Patients. Three approaches were used to recruit patients. Two practices known to offer email consultation displayed posters in their waiting rooms leading to the recruitment of three patients. GPs participating in the study were asked to provide recruitment materials to patients with whom they communicated via email; this led to the recruitment of a further three patients. In order to vary the sample according to the maximum variability framework, the remaining patient participants were recruited via an advertisement placed on a London-based community website. Many queries were received via the website but only patients who fulfilled the eligibility criteria could be included.

Potential participants were sampled to saturation, and the advertisement was removed as soon as this was reached. All recruitment materials were devised by one of the researchers in conjunction with two of other authors.

\section{Interviews}

Interviews took place from March until November 2010. They were conducted by the lead author, who was, at the time, a doctoral student in health services research, with a background in public health and anthropology, and training in qualitative interviewing. Interviews were conducted as follows:

- GPs - at their place of work;

- patients - a neutral venue, for example, a local cafe or at the host institution (Imperial College London); and

- experts - at their place of work, their home, or the host institution.

Interviews lasted between 20 and 60 minutes. The topic guide that was used to inform them had been piloted with colleagues (GPs and non-academic staff) before the study commenced and then refined iteratively throughout the study. The final version covered four main areas:

- experiences of using email consultation;

- opinions of using email consultation; 
Table 1. Patients' and GPs' characteristics and participant email use

\begin{tabular}{|c|c|c|}
\hline Characteristic & Patients, $n(\%)$ & GPs, $n(\%)$ \\
\hline Total number & $14(100)$ & $10(100)$ \\
\hline \multicolumn{3}{|l|}{ Sex } \\
\hline Male & $9(64)$ & $4(40)$ \\
\hline Female & $5(36)$ & $6(60)$ \\
\hline \multicolumn{3}{|l|}{ Age, years } \\
\hline $16-24$ & $2(14)$ & - \\
\hline $25-64$ & 11 (79) & - \\
\hline$\geq 65$ & $1(7)$ & - \\
\hline \multicolumn{3}{|c|}{ Highest educational attainment } \\
\hline Secondary school & $1(7)$ & - \\
\hline Further education & $4(29)$ & - \\
\hline Higher education & $9(64)$ & - \\
\hline \multicolumn{3}{|l|}{ Date of qualification ${ }^{a}$} \\
\hline 1970-1979 & - & 3 (30) \\
\hline 1980-1989 & - & $5(50)$ \\
\hline 1990-1999 & - & 0 \\
\hline 2000-2009 & - & $2(20)$ \\
\hline Practice list size (range) & $5293-15762^{a}$ & $5293-15762$ \\
\hline \multicolumn{3}{|l|}{ Participant email use } \\
\hline \multicolumn{3}{|l|}{ Duration of email use } \\
\hline Minimum, months & 2 & 6 \\
\hline Maximum, years & 4 & 7 \\
\hline \multicolumn{3}{|l|}{ Frequency of email use } \\
\hline Per episode of care & $3-10$ & Not known \\
\hline Per month & $2-10$ & $0-31$ \\
\hline \multicolumn{3}{|l|}{ Type of email use } \\
\hline Standard email & 13 & 9 \\
\hline Web messaging & 1 & 2 \\
\hline
\end{tabular}

\section{Box 1. Patient-reported health condition prompting consultation $(N=10)$}

- Recovery from severe head injurya

- Pregnant

- Lump in breast

- Asthma/Eczema

- Torn knee ligament

- Contraception-related queries

- Arthritis and sciatica

- Abscess in armpit

- Hypertension

${ }^{a} n=2$. used; and use.

\section{Analysis}

\section{RESULTS}

In total, 30 interviews were undertaken, with 14 patients, 10 GPs, and six experts. Demographic information is presented in Table 1. Patients came from 12 different general practices with three participants attending the same practice; their GP also took part in the study. Three GP participants also had a patient participating in the study.

When asked to estimate how many emails they usually sent, patients' range was between 2 and 10 emails a month; for GPs, this was between 0 and 31 emails a month (Table 1). Patients were not required to disclose their reasons for seeking healthcare but 10 volunteered this information (Box 1). The expert participants were:

- a practice manager involved in implementing a secure email consultation system in their general practice;

- an ethicist;

- a chief information officer (ClO) representing three primary care trusts;

- a policymaker in England;

- a policymaker working for a not-for-profit organisation in Europe; and

- the managing director of a company providing e-consultation software in Denmark (market leader with $40 \%$ of users having their software).

The analysis of 30 interviews produced four overarching themes:

- understanding how email consultation is

- identifying barriers and facilitators to its

Interviews were digitally audiorecorded and transcribed by an external transcription company. All transcripts were validated against the recorded material by the interviewer. Data were analysed thematically and Atlas.Ti (version 6) was used to guide that analysis. The interviewer coded all data, and two of the other researchers coded samples of transcripts. Analysis was carried out concurrently with data collection, with emerging themes probed in subsequent interviews. Two of the researchers oversaw analysis of coded transcripts. Quotes are identified as coming from patients (PT), GPs (GP), or experts (EX), with each participant having a unique identifying number from 0 to 30. Demographic details of the person quoted are also included.
- initiators for using email consultation;

- motivators for ongoing use;

- impact of use; and

- management of use.

\section{Initiators}

Participants described email consultation being initiated on an ad hoc basis, prompted by logistical or practical problems. The wider popularity of email played a part in initiating its use.

Patients and GPs reported that they started using email as a consultation method because there was a need for an alternative method of communication when it was difficult for the patients to physically attend an appointment, such as being overseas or mobility restrictions:

'I mean he's, he always says as well, because I can't manage the stairs. He always says, you can always email me.' (PT12, female, 25-64 years) 
Once this kind of contact was established, it opened a communication channel that was further used. Contact was largely initiated by the patients:

It's usually initiated by the patient, or as a request by the patient - "Is there any way I could ...?" - as opposed to us offering it. (GP8, male, full-time GP)

From the GP perspective, initiation was linked to email being the norm, with its introduction in practice inevitable due to the popularity of email:

Uh, patients want it, and a lot of patients, um, because, uh, particularly [the] younger generation, everything's done on email now, isn't it?' (GP5, female, part-time GP)

\section{Motivators}

Once GPs and patients had engaged in email consultation, they continued to use it. Both groups were motivated to do so because of the convenience that email brought and because of the alternative route it provides for communication between GP and patient.

Convenience. Both groups were positive about the convenience that email offers, with advantages ranging from its 'efficiency' and 'speed' to specific characteristics like asynchronicity and the written format:

I think it actually enhances communication because when something is written it can be more thought out and you can be more explicit, since you have more time to think about what you're writing - and it can be more detailed.' (PT3, female, 25-64 years)

In addition, email can fit in with a patient's life, for instance making it easier to communicate with the GP while at work. For GPs, email allows them to avoid telephone tag with working patients:

... because you call, they [the patient] say, "Oh, I just can't talk at the moment. Because the way offices are, you know, open plan and things, I can't talk".' (GP9, female, part-time GP)

The medical ethics expert felt that benefits could be considerable in relation to convenience and efficiency:

'So, in terms of the benefits versus the harms, potential benefits would be quite considerable in terms, if it turns out to be more efficient a use of time ... and a more convenient use of time.' (EX4, medical ethicist)

Alternative access. Patients expressed dissatisfaction with current routes of access to their GP:

'No, I only called because you usually have to call in the morning to get an appointment, so there's a bracket of time. It's after 8:30 is when they open so you have to call then pretty much every single minute just to try and get through. '(PT10, male, 25-64 years).

Email consultation allowed patients to achieve direct contact with their GP, bypassing the usual procedure, which involves contacting reception, in the first instance. The ability to bypass the usual structures, which have been put in place to control access to healthcare services, is regarded as special:

'It makes it feel like she's more there for me, because it makes me feel like she's there for me even when I'm not just seeing her, because she's happy for me to email her. So it does make it feel like it's a, a better service that I'm getting from her. So I think it just makes me feel more in touch with her, and more as though she's there.' (PT1, female, 25-64 years)

In cases whereby patients had a relationship with a specific doctor, email was seen as promoting and maintaining that relationship, allowing GPs to deliver personalised care:

I think people like to know that they can talk to their doctor directly, as opposed to having to go through several tiers of, you know, telephonist, you know, receptionist, secretary. '(GP7, female, GP registrar)

\section{Impact of use}

The introduction of email consultation led to workload and safety concerns. Uncertainty around the use of email as a consultation method was revealed as a major concern by both GPs and patients.

Workload. Workload difficulties arose because email is not integrated into practice, time is not allowed for 'extra' consultations and, in some cases, GPs reported that email was generating more work and additional consultations. This was supported by patient accounts that they were consulting about concerns for which they would not otherwise have contacted the practice: 
'... because I think, "Oh, God, I have to make an appointment, I have to go there, so let's forget about it".' (PT13, female, 25-64 years)

The policymaker participant recognised workload as a potential concern for GPs using email consultation:

'There are two or three things that people have worried about. One is, obviously, it's not for everyone, but also, you know, if we do this, what's the workload? Is it going to take us longer than before? Is that going to be allowed for, contractually?' (EX1, policy maker)

Safety. All participants in the study expressed concerns about data safety. These were largely based on potential negative scenarios, rather than on actual experience:

And ... and ... there's this is kind of which I'm sure has come up in your other conversations - but this kind of feeling that, in some way, what if they're lost, or missed, or someone doesn't pick it up, or if I'm not here, who will manage it?' (GP8, male, fulltime GP)

Some GPs had experienced potential safety breaches:

And actually just 2 weeks ago, I had a patient emailing the practice. I mean, I say 'l', but it's up in my court usually, who basically said: "I wonder if you could recommend a, a counsellor, I'm feeling quite suicidal". So, I then, you know ... that came to my ... fortunately, it was looked at that day. '(GP11, female, full-time GP, partner)

Another experienced inappropriate patient behaviour when using email:

And one of my colleagues gave him my email address and that wasn't something I would [have done]. He wasn't someone I would necessarily have chosen, and I then got probably about 10 emails from him every week, and, we had to sort of make some very strong ground rules about those.' (GP5, female, part-time GP)

Lack of rules of engagement. GPs in the study had adopted email consultation without any agreed, or negotiated, rules of engagement. This lack of structure meant that both patients and GPs were not sure how to behave when using email consultation:

'Well, I, I, I've, speaking personally I think, it still feels quite tentative and, in a sense, it hasn't been formalised or given a structure. (PT14, male, $\geq 65$ years)

The lack of rules extended to disagreement over what constituted an email consultation, with individual GPs having different perspectives on what is appropriate:

I guess I want clarity about what the dialogue was. Is it actually a consultation? Or is it actually a request for a little bit more information, or what?' (GP8, male, full-time GP)

\section{Management of use}

Both GPs and patients attempted to mitigate the effects on workload, improve safety, and introduce rules of engagement.

Workload. GPs attempted to place boundaries around their email use, using email only with selected patients. The implication was that the chosen patients were less likely to abuse it:

'Yes, well I think it's ... you know, it is, it is very personal and I, I certainly wouldn't dream of saying to all my patients "Please email me whenever you like", because that will be just crazy. But there are the few that, maybe, you're concerned about and, you know, have a particular need.' (GP6, female, full-time GP, senior partner)

They set their own version of rules:

'Before I've used email, I've always made some ground rules with the patients.' (GP5, female, part-time GP)

Patients were conscious of GP workload and actively sought not to bombard the GP with emails:

'Because he was, like, obviously, you know, as I've said, "Oh, you can email me if you've got a problem. You know, just email me". It's like a bit when people say, like, you know... "Make yourself at home". It doesn't really mean ... it as much as [laughs] It doesn't mean kick off your shoes. So when he's saying, like, "Just email me if you've got a problem", it doesn't mean email me every 3 days, you know.' (PT7, male, $16-24$ years)

Safety. Both GPs and patients attempted to address potential safety issues by placing safeguards around the use of email. GPs created rules to enable them to control safety concerns and manage risk. For 
example, they informed patients that they may not receive a response immediately:

'There are ... yes, l've all ... I always say to patients "If you email me, there is a risk I may not be here, and there is a risk that you won't get a reply and, if you don't, then you must do ... contact somebody else in the surgery".' (GP6, female, full-time GP, senior partner)

Uncertainty. Both patients and GPs tried to manage the uncertainty around email consultation use. Patients applied social norms associated with day-to-day life:

'But no, I just keep it very professional and just, you know, stick to the, the symptoms and what can [be done] ...' (PT12, female, 25-64 years)

In addition, GPs applied their previous experience and usual professional standards when trying to control the use of email consultation:

Well I did it as the same as any consultation, because you receive phone calls from patients, you receive letters from patients, you see them face to face and, as in all of them, you've got to putyourself in the position to make a diagnosis or management plan that's safe and reasonable.' (GP10, male, full-time GP, partner)

Both patients and GPs acted with a view to sustaining a functioning relationship. Patients were especially conscious that they should not be seen to be abusing the relationship:

And obviously he, he was always okay with the idea of, of me emailing him. But I had to spread it out. I didn't like to ... I, I couldn't do that every day, or, or like every 2 days.' (PT7, male, 16-24 years

Both GPs and patients agreed that email consultation is not suitable for all patients, or for every situation.

There was recognition of the need for regulation and guidance in using email consultation:

I think either we can do a couple of things: we can either help them put some protocols in place so that what they are doing is done in a fairly safe way ... which is what l'd rather do, because, you know, sometimes you can ... People can over-react and say, "Right, well, we'll just ban it. We'll just ban all of them".'(EX2, chief information officer)
For users, the motivators outweighed the problems associated with email consultation. Despite the uncertainty and the safety incidents described, GPs and patients persisted in using email consultation because of the benefits it brought.

\section{DISCUSSION}

\section{Summary}

Email consultation in primary care is initiated where it is deemed a practical alternative to face-to-face and/or telephone contact and is seen as a viable option given its wider popularity. Once initiated, use continues, as email consultation is deemed convenient for GPs and patients, and offers a different type of communication that is direct and asynchronous.

The positive attributes of email led to its use for consultation, but are also associated with GPs having concerns about workload and both GPs and patients having concerns about safety. In the face of these challenges, both GPs and patients managed the impact of using email consultation by placing boundaries around use based on previous experience: while GPs drew on experience with other methods of consultation, patients drew on social norms. There was recognition that long-term concerns about email consultation use would need to be addressed by regulation and guidance.

\section{Strengths and limitations}

This study included a wide range of participants who reported varying frequencies and duration of email use. A major strength was the coherence of findings between the three participant groups. Saturation was reached in the sample, but it is not possible to discount that further interviews might have led to small differences in emphasis. The study was set in London and so the transferability of the findings outside of this setting may be questionable. However, as patterns of email consultation use are not currently known, this is not possible to determine.

Although maximum variability in the sample was aimed for, this was offset by the need to identify people who were using email consultation. Recruitment of GPs was more difficult than for patients because GPs were reluctant to admit to having this type of contact with their patients. Snowballing seemed to be more effective as a recruitment approach, as it led the researchers to GPs who had already talked to other GPs about their use of this type of communication. This should be considered in any future studies.

Inclusion of a GP or practice manager 
in the study did not necessarily ensure participation of their patients; this was due, not only to a reluctance to talk about email consultation use, but also interpractice differences of opinion - even where systems for email consultation were in use.

There were no carers or nurses recruited to the study. This may reflect their lack of involvement in email consultation but determining this was beyond the scope of this study. Patient participants were largely educated to higher level (degree level and above) and only one was aged $\geq 65$ years. As there is speculation that older adults and those in lower socioeconomic groups are more likely to be left behind in relation to the uptake and use of new technologies, ${ }^{24}$ this may reduce the transferability of the findings.

One author coded the dataset with sections of coding checked by two other authors (a GP and a sociologist). If resources had allowed, it would have been appropriate to obtain a secondary code of the entire dataset; however because of limitations on time and funding it was not possible to do this. The contrasting perspectives of the two authors who checked data coding was considered a strength of the study.

Helen Atherton was funded during the conduct of this study by a Medical Research Council Studentship at Imperial College, London, and during final analysis and write up by a NIHR SPCR Fellowship at the University of Oxford.

\section{Ethical approval}

Informed consent was gained from all participants. Ethical approval and research governance approval were granted by Brompton, Harefield and National Heart and Lung Institute Research Ethics Committee (reference number: 09/ H0708/70).

\section{Provenance}

Freely submitted; externally peer reviewed.

\section{Competing interests}

The authors have declared no competing interests.

\section{Acknowledgements}

We would like to thank all participants. We would also like to thank Dr Josip Car and Professor Azeem Majeed at Imperial College London for their assistance during the conduct of this study. We would like to thank the PCRN for their assistance with recruitment.

\section{Discuss this article}

Contribute and read comments about this article on the Discussion Forum: http://www.rcgp.org.uk/bjgp-discuss

\section{Comparison with existing literature}

The GPs in this study recognised the increasing popularity of email as an initiator for email use. This perspective has been demonstrated in UK-based GPs, who were not using email for consultation. ${ }^{28}$ Until now, it has not been identified in those who actively engage in this type of interaction.

Other studies have identified motivators for email consultation use in different settings and populations. In a secondarycare setting, email consultation has been shown to facilitate access to a clinician, providing a communication channel..$^{29}$ In Norway, patients felt email consultation was positive in allowing them easier access to their general practice..$^{30}$

Impact of use has also been recognised in the US where physicians who were using email consultation with their patients expressed worries about email becoming a burden. ${ }^{31}$ In secondary care, patients have reported privacy concerns ${ }^{32,33}$ and physicians have expressed worries about email not reaching them in a timely manner. ${ }^{31}$ The ad-hoc management of email consultation, as seen in this study, has been described in surveys of doctors, where they have reported, for example, not putting personal details into emails $a^{31} d^{31}$ devising their own systems for putting emails into the record.?

\section{Implications for research and practice}

Clinicians in primary care face pressure to introduce email consultation; this has come from both patients and policymakers. As a result, clinicians are developing idiosyncratic usage patterns based on their individual clinical experience. Practices should be aware of, and should address, such use.

Email consultation is attractive to policymakers; it has the potential to provide patients with personalised and convenient care, as well as better access to primary care. However, the drive to introduce email consultation into general practice must consider the extraresponsibilityand workload faced by clinicians in adopting a new method of consultation, and the changes required in the general practice setting to ensure its safe use. The current stance of professional bodies representing the medical profession (such as the British Medical Association and the Royal College of General Practitioners), has been to refrain from providing guidance on email consultation use, however, creating guidance should be their foremost concern in supporting those who are expected to put government policies into practice. At this point, email consultation could be brought in line with other methods of consultation. To ignore the need for guidance on email consultation may, in fact, lead to serious safety breaches and care that is less than optimal for patients.

The results of this study indicate that more evidence on email consultation use is needed. Key areas that warrant further research include:

- understanding with which patients email is best used and what for;

- the effect of email consultation on workload; and

- the safety of email consultation.

Research should focus on how best to integrate email consultation into the general practice workload, and maximise the benefit it can bring.

Email consultation is being used in primary care in an unregulated and unstructured way. It is initiated because it brings benefits, but it is associated with uncertainty about how to ensure that it is safe, that workload will not be prohibitive, and that patients are satisfied. At this early stage in its use, there is scope to put in place a supportive regulatory framework via guidance from professional bodies, as well as a practice organisation that accounts for, or even promotes, its use. 


\section{REFERENCES}

1. Dutton WH, Helsper EJ, Gerber MM. Oxford Internet Surveys. The internet in Britain 2009. Oxford Internet Institute University of Oxford. http://umw.oii.ox.ac. uk/research/oxis/oxis2009 report.pdf (accessed 8 Oct 2013).

2. Liddell A, Adshead S, Burgess E. Technology in the NHS: transforming the patient's experience of care. http://www.kingsfund.org.uk/publications/ technology-nhs laccessed 8 Oct 2013).

3. Dixon RF. Enhancing primary care through online communication. Health Aff 2010; 29(7): 1364-1369.

4. American Medical Association. Opinion 5.026 - the use of electronic mail. http://www.ama-assn.org//ama/pub/physician-resources/medical-ethics/codemedical-ethics/opinion5026.page laccessed 8 Oct 2013).

5. Menachemi N, Prickett CT, Brooks RG. The use of physician-patient email: a follow-up examination of adoption and best-practice adherence 2005-2008. J Med Internet Res 2011; 13(1): e23.

6. Ortega Egea JM, González MVR, Menéndez MR. eHealth usage patterns of European general practitioners: a five-year (2002-2007) comparative study. Int J Med Inform 2010; 79(8): 539-553.

7. Braunold G. Survey on the future of IT. 2010 http://uww.pulsetoday.co.uk/maincontent/-/article_display_list/11035181/survey-on-the-future-of-it [accessed 27 Sep 2013].

8. Whitfield L. Netscape navigators. http://www.ehi.co.uk/insight/analysis/1038 [accessed 27 Sep 2013].

9. Hobbs J, Wald J, Jagannath YS, et al. Opportunities to enhance patient and physician e-mail contact. Int J Med Inform 2003; 70(1): 1-9.

10. Ministry of Social Affairs and Health Finland. eHealth Roadmap. http://www.stm fi/en/publications/publication/-/_julkaisu/1056833 [accessed 27 Sep 2013]

11. Ministry of Public Health, Wealth and Sport, Netherlands. National policy document on health: Health close to people. http://www.government.nl documents-and-publications/leaflets/2012/05/11/health-close-to-people.html [accessed 27 Sep 2013]

12. Australian Government. Improving primary health care for all Australians. http:// wuw.yourhealth.gov.au/internet/yourHealth/publishing.nsf/Content/improvingprimary-health-care-for-all-australians-toc/\$FILE/Improving\%20Primary\%20 Health\%20Care\%20for\%20all\%20Australians.pdf [accessed 27 Sep 2013]

13. Department of Health. The power of information: putting all of us in control of the health and care information we need. http://informationstrategy.dh.gov.uk [accessed 27 Sep 2013].

14. Health Canada. Healthcare system: eHealth. 2010. http://www.hc-sc.gc.ca/hcssss/ehealth-esante/index-eng.php laccessed 8 Oct 2013).

15. Danish Ministry of Health. eHealth in Denmark: eHealth as a part of a coheren Danish health care system. http://www.sum.dk// /media/Filer\%20-\%20 Publikationer_i_pdf/2012/Sundheds-IT/Sundheds_IT_juni_web.ashx [accessed 27 Sep 2013].

16. Silvestre AL, Sue VM, Allen JY. If you build it, will they come? The Kaiser Permanente model of online health care. Health Aff 2009; 28(2): 334-344.
17. American Academy of Family Physicians. e-visits. http://www.aafp.org/about/ policies/all/e-visits.html laccessed 8 Oct 2013).

18. Stacey R. The Medical Protection Society. Do's and don'ts of emailing patients. [updated 2010/04/26/]; 10-2]. http://www.medicalprotection.org/uk/sessional-gp/ issue-1/dos-and-donts-of-emailing-patients laccessed 8 Oct 2013).

19. BMA General Practitioners Committee. Developing general practice: listening to patients. http://www.bma.org.uk/employmentandcontracts/independent contractors/managing_your_practice/listenpatient.jsp [accessed 27 Sep 2013]

20. Royal College of General Practitioners. Patient Online: The Road Map. 2013. http://www.rcgp.org.uk/clinical-and-research/practice-management-resources/ health-informatics-group/patient-online.aspx laccessed 8 Oct 2013).

21. Cuzner E. Medico-legal dilemmas posed by advances in computer technology Good Practice 2010; 1: 4-6.

22. Atherton H, Car J, Meyer B. Email for clinical communication between patients/ caregivers and healthcare professionals. Cochrane Database Syst Rev 2012; 11: CD007978.

23. Barratt D. Sky Blue Medical Group. http://skybluemedicalgroup.co.uk/html contact_us.html laccessed 8 Oct 2013).

24. Car J, Sheikh A. Email consultations in health care: 1 - scope and effectiveness. BMJ 2004; 329(7463): 435-458.

25. Goodwin N, Dixon A, Poole T, Raleigh V. Improving the quality of care in general practice: Report of an independent inquiry commissioned by The King's Fund. http://www.kingsfund.org.uk/publications/gp_inquiry_report.html [accessed 27 Sep 2013].

26. Potts HW, Wyatt JC. Survey of doctors' experience of patients using the internet. J Med Internet Res 2002; 4(1): e5.

27. Karsenti T, Charlin B. Information and communication technologies (ICT) in medical education and practice: the major challenges. Int J Tech Higher Edu 2008; 5(2): 68-81.

28. Hanna L, May C. Fairhurst K. The place of information and communication technology-mediated consultations in primary care: GPs' perspectives. Fam Pract 2012; 29(3): 361-366

29. Bergmo TS, Wangberg SC, Schopf TR, Solvoll T. Web-based consultations for parents of children with atopic dermatitis: results of a randomized controlled trial. Acta paediatrica 2009; 98: 316-320.

30. Tjora A, Tran T, Faxvaag A. Privacy vs usability: a qualitative exploration of patients' experiences with secure Internet communication with their general practitioner. J Med Internet Res 2005; 7(2): e15.

31. Patt MR, Houston TK, Jenckes MW, et al. Doctors who are using e-mail with their patients: a qualitative exploration. J Med Internet Res 2003; 5(2): e9.

32. Hsiao AL, Bazzy-Asaad A, Tolomeo C, et al. Secure web messaging in a pediatric chronic care clinic: a slow takeoff of kids airmail. Pediatr 2011; 127(2): e406-e413.

33. Houston TK, Sands DZ, Jenckes MW, Ford DE. Experiences of patients who were early adopters of electronic communication with their physician: satisfaction, benefits, and concerns. Am J Manag Care 2004; 10(9): 601-608. 